American Journal of Agricultural and Biological Sciences 7 (2): 201-206, 2012

ISSN 1557-4989

(C) 2012 Science Publications

\title{
Evaluation of Vegetables Farmers Participation in Agricultural Extension Activities
}

\author{
Mohammad Altarawneh, Ebraheem Altahat and Ali AL-Sharafat \\ Department of Agricultural Economics and Extension, \\ Faculty of Agriculture, Jerash University, Jerash, 26150, Jordan
}

\begin{abstract}
Problem statement: Farmers's participation in extension activities is one of the most important issues facing extension providers in Jordan. The determination of the reasons that prevent farmers from participation in some extension activities is another problem. This study was conducted to evaluate the level of vegetables farmers' participation in agricultural extension activities in the Dear Alla area of Jordan and to investigate the reasons that prevent farmers' participation in agricultural extension activities. Approach: The study investigated farmers' socioeconomic characteristics, extension activities, farmers' opinion concerning the activities and the degree of participation of farmers regarding the conducted activities. The study was conducted to cover the Dear Alla area. The dear Alla area is one of the most important vegetable production areas of the Jordan Valley. The population of this study included all the vegetable farmers in this area. Results: The sample obtained through the simple random sampling technique. A total number of 320 vegetable farmers were selected. A structured questionnaire was designed to obtain information from farmers. The questionnaire consisted of two main parts; the first part was related to personal and socioeconomic characteristics of the sample individuals. The second part was related to extension activities. Conclusion/Recommendations: High, medium and low levels of interviews farmers' participation in agricultural extension activities were noticed. Three activities resembled $43 \%$ of the total investigated activities (7 activities) were high in the degree of farmers' satisfaction indicating high levels of farmers' participants. Other three activities were with medium level and also resembled $43 \%$ of the total investigated activities. The remaining activity was low in participation and resembled $14 \%$ of the total investigated activities. The date of the activity is not suitable for farmers and the preoccupation with another concern or job resembled $60 \%$ of the reasons for farmers not to participate in agricultural extension activities. The other three reasons: (Does not know the date of activity, unwillingness to participate and activities do not meet their needs) resembled the remaining $40 \%$ of the reasons for the interviewed farmers not to participate. In the light of the findings of the study extension activities should be planned with full involvement of farmers to increase their level of participation and using local leaders as contact farmers could enhance farmer participation and will be beneficial in this regard.
\end{abstract}

Key words: Participation, extension, agricultural extension activities, satisfaction

\section{INTRODUCTION}

Agricultural extension activities represent the main element in the agricultural production process. It is the motive to develop and increase production. In Jordan, the agricultural extension activities considered to be one of the most important activities in achieving the comprehensive rural development by transferring technologies from research stations to the farmers (Khalil, 2007). Many countries established their agricultural extension systems in order to realize their national food security goals (Swanson, 2006). Success of agricultural extension programs depends largely on the optimal selection of extension activities; methods, goals and the farmers' preference of extension methods (Seevers, 1997). More open employee friendly organization policy has proved to enhance employee work performance (Tella et al., 2007). Agricultural extension by its nature has an important role in promoting the adoption of new technologies and innovations (Shamsudin and Yap, 2011). 
Extension methods and procedures effects on results of extension programs are obvious in any agricultural extension program. The results are highly related to the procedures, which in turn affected by the socioeconomic characteristics of the farmers. It is very important to investigate these characteristics (Vergot et al., 2005).

In order to deploy an appropriate technology for extension service, financial, social, human and organizational sustainability should be achieved over time and policies that provide affordable access to information need to be carefully identified and examined (Hosseini et al., 2009). Performance of extension agents is expected to increase if they have program development competencies and to keep extension agents competent and to further improve their performance, these competencies must be considered and upgraded and continuous assessment of extension agents' competencies and performance is recommended (Tiraieyari et al., 2010). The assessment process of the extension agents' has direct relation with measuring the attitudes of the farmers towards the provided agricultural extension services by those agents. The effectiveness of extension services is also highly dependent on the ability of extension workers who are competent as the whole extension process is dependent on them to transfer information from extension organizations to the clients.

The participation of farmers in extension activities means that they contribute actively and interact with the extensionists (Maunder, 1972). The emergence of participation as an issue to be addressed within extension approaches was slower in coming to the forefront, as compared to the attention participation received within research systems. One key element of participation is an emphasis on developing the capacity of local people as an end in itself, as opposed to the purely mechanistic emphasis of participation as a means within the technology development flow that has often characterized research and extension programs (Chambers et al., 1989). The involvement of local groups in the planning of Agricultural extension programs, decision making and problem solving of economic and agricultural issues requires the allocation of appropriate resources for this work (Dennehy et al., 2000). The increase in farmer participation in sustainable agricultural development programs and agricultural extension services, decentralizing from activities and facilitating to apply local groups are the most important approaches for Agricultural extension in future (Allahyari, 2009).

During the late 1980s and early 1990s of the past century, increasingly more field-based experiences emerged creating more space for methodological and institutional innovations for agricultural research and extension. Within these participatory approaches-as they became commonly known-a special emphasis was placed upon participation of local people and their communities, especially working with and through groups; and building upon the traditional or indigenous knowledge that they held (Waters-Bayer, 1989; Haverkort et al., 1991). Haverkort et al. (1991) presents a (general) typology of participation in extension which attempts to qualify levels of intensity of farmer participation as participation in extension meetings or activities, participatory diagnoses (e.g., participatory rural appraisal, problem-census) and participation through organization. Using this typology, much of what is called farmer participation in extension falls under the first two levels.

Farmer participation in extension requires putting farmers first by placing real ownership and accountability of public extension organizations into the hands of the clients -the farmers and their communities and organizations. Antholt (1994) suggests that this might be accomplished by developing mechanisms for improving public support (i.e., cost-sharing, local taxes) that would provide resources to farmers and their organizations and allow them to choose the types of extension services that are most relevant to their needs.

The main objective of this study was to evaluate the level of vegetables farmers' participation in agricultural extension activities in Dear Alla area of Jordan. The study investigated farmers' socio-economic characteristics, extension activities, farmers' opinion concerning the activities and the degree of satisfaction of farmers regarding the conducted activities.

\section{MATERIALS AND METHODS}

The sample: This study was conducted to cover Dear Alla area. Dear Alla area is one of the most important vegetables production areas of the Jordan Vally. The population of this study included all the vegetable farmers in this area. The sample obtained through simple random sampling technique. A total number of 320 vegetable farmers were selected at random for this study. The sample size was determined according to the following equation:

$\mathrm{n}=\left[\left(\right.\right.$ p. q. $\left.\left.\mathrm{z}^{2}\right) / \mathrm{e}^{2}\right] /\left[\left(\mathrm{N} \cdot \mathrm{e}^{2}\right)+\left(\mathrm{z}^{2} \cdot \mathrm{p} \cdot \mathrm{q}\right) /\left(\mathrm{N} \cdot \mathrm{e}^{2}\right)\right]$

Where:

$\mathrm{n}$ = Sample size

$\mathrm{p}=$ The proportion that the sample will occur 
Table 1: Activities used to measure farmers' satisfaction

\begin{tabular}{ll}
\hline Activity no. & Activity \\
\hline 1 & Agricultural exhibitions \\
2 & Workshops \\
3 & Seminars, lectures and discussions \\
4 & Extension fields \\
5 & Leaflets \\
6 & Field visits \\
7 & Office visits \\
\hline
\end{tabular}

Source: Prepared by the researchers

$\mathrm{q}=$ The proportion that the sample will not occur $=$ (1- p)

$\mathrm{z}=$ The standardized score

$\mathrm{e}=$ Error term

$\mathrm{N}=$ Population

The sample size was determined at a confidence level of 0.95 ; this level was an appropriated level due to the reason that the population itself was relatively small in size. The term error was 0.05 and the $\mathrm{Z}$ value correspondent to this level is 1.96 , the proportion that the sample will occur was 0.50 and proportion that the sample will not occur was also 0.50 and the population was 1675 . The sample size according to the above mentioned equation was 311. Additional 9 farmers were interviewed:

$\mathrm{n}=\left[\left(\mathrm{p} \cdot \mathrm{q} \cdot \mathrm{z}^{2}\right) / \mathrm{e}^{2}\right] /\left[\left(\mathrm{N} \cdot \mathrm{e}^{2}\right)+\left(\mathrm{z}^{2} \cdot \mathrm{p} \cdot \mathrm{q}\right) /\left(\mathrm{N} \cdot \mathrm{e}^{2}\right)\right]$

$\mathrm{n}=\left[\left(0.5 \times 0.5 \times 1.96^{2}\right) / 0.05^{2}\right] /\left[\left(1675 \times 0.05^{2}\right)+\right.$

$\left.\left(1.96^{2} \times 0.5 \times 0.5\right) /\left(1675 \times 0.05^{2}\right)\right]$

$\mathrm{n}=311$

Survey and data collection: A structured questionnaire was designed to obtain information from farmers. The questionnaire consisted of two main parts; the first part was related to personal and socio-economic characteristics of the sample individuals. The second part was related to extension activities. To measure the degree of farmers' satisfaction five point Likert-type scale was used. Ratings on a 7 item Likert-type were used to represent the activities involved. The ratings ranged from 1 (strongly not satisfied) to 5 (strongly satisfied) as follows: 1: strongly not satisfied, 2: not satisfied, 3: slightly satisfied, 4: satisfied, 5: strongly satisfied.

The activities used to measure farmers' satisfaction are shown in Table 1. A reliability estimate (Cronbach alpha) was computed for the Instrument of data collection and it was determined to be appropriate for this study (0.82).

Data analysis: The data collected was analyzed using descriptive statistics such as percentages, minimum, maximum, mean, ranking and correlations. A quantitative analysis using Likert scale was used. Both analyses were employed to analyze socio-economic information of farmers' and participation level in the study area. All analyses were conducted to answer the specific objectives of the study. In the Likert scale a numerical value is assigned to each potential choice and a mean figure for all the responses is computed at the end of the evaluation or survey. The final average score represents overall level of satisfaction toward the activity assigned. The Statistical Package for Social Sciences software (SPSS) was used in the analysis process.

\section{RESULTS}

Table 2-5 show a summary of the results obtained from the study. Table 2 shows the socioeconomic characteristics of investigated sample, while Table 3 shows the degree of farmers' satisfaction about the agricultural extension activities and Table 4 shows the reasons prevent farmers from participation in extension activities.

\section{DISCUSSION}

Table 2 shows that the most effective category in extension activities participation is the category 40-60 years of age. This category is characterized by maturity in decision making and agricultural experience. It represents $58 \%$ of the interviewed sample. Concerning the education level, it is obvious that college graduates represent the majority of the interviewed individuals. The primary level is next then the illiterate and secondary level respectively. This inequality of scientific degree requires to be taken in consideration when preparing agricultural extension programs and extension methodologies. Table 2 also shows that more than one half of the interviewed farmers $(53 \%)$ consider agriculture as a main job. This implies that more attention should be paid to this category and extension programs should consider largely this category when implementing agricultural extension programs. The table also shows that the income of almost $2 / 3$ of the interviewed farmers is less than $500 \mathrm{JDs} /$ month. Extension programs and methodologies must be properly oriented to those farmers in order to enhance the contribution of their agricultural activities to their income.

Table 3 shows the mean score by activity in rank order, as well as, the overall level of satisfaction toward agricultural extension activities. The mean score of the items in the scale represent the farmers' satisfaction 
towards agricultural extension activities. Results revealed that the farmers' overall mean score for satisfaction was 3.49 , indicating a positive attitude and high satisfaction toward agricultural extension activities. This high level of satisfaction resembles high level of participation in the activities. This means that we can depend on the level of satisfaction to determine the level of participation of the farmers in activities. Farmers' rated field visits, office visits and extension fields with the highest degree of satisfaction with means of $4.35,4.13$ and 3.92 respectively. This indicates that the farmers were participating effectively in those three activities compared to the other extension activities. The activities which received the lowest degree of satisfaction were the first (agricultural exhibitions) and the fifth (leaflets) with mean scores of 2.78 and 2.93 respectively. The results revealed a moderate level of farmers' participation in workshops activity, seminars, lectures and discussions activities with mean scores of 3.15 and 3.19.



Medium $43 \%$

Fig. 1: Levels of interviewed farmers' participation in extension activities

Table 2: Socio-economic characteristics of investigated sample

\begin{tabular}{lcr}
\hline Item & Number & $(\%)$ \\
\hline Age (Years) & & \\
$<40$ & 054 & 17 \\
$40-60$ & 185 & 58 \\
$>60$ & 081 & 25 \\
Total & 320 & 100 \\
Education level & & \\
Illiterate & 059 & 18 \\
Primary & 087 & 28 \\
Secondary & 054 & 17 \\
College & 120 & 37 \\
Total & 320 & 100 \\
Main job field & & \\
Agriculture & 170 & 53 \\
Public sector & 060 & 19 \\
Private sector & 090 & 28 \\
Total & 320 & 100 \\
Income (JDs/ Month) & & \\
$\quad<500$ & 220 & 69 \\
500-750 & 070 & 22 \\
$>751$ & 030 & 09 \\
Total & 320 & 100 \\
\hline Source: Prepare & &
\end{tabular}

Source: Prepared by the researchers based on the study survey
Figure 1 shows the levels of interviewed farmers' participation according to levels of satisfaction of the farmers in activities. Percentages in the figure based on considering three levels of participation according to the levels of satisfaction. Three activities were high in the degree of farmers' satisfaction indicating high level of farmers' participation. These three activities resemble $43 \%$ of the total investigated activities. Other three activities were medium in the degree of farmers' satisfaction indicating medium level of farmers' participation. These three activities resemble also $43 \%$ of the total investigated activities. The remaining activity was low in the degree of farmers' satisfaction indicating low level of farmers' participation. This activity resembles $14 \%$ of the total investigated activities. These levels (levels of participation) were determined according to average degree of satisfaction (Table 4).

From data presented in Table 4 we deducted levels of participation of interviewed farmers in agricultural extension activities. From the table we concluded that there is a variable level of farmers' participation in the activities. This variation is attributed to several reasons. These reasons should be considered when preparing agricultural extension programs. Table 5 shows the most dominant reasons for the farmers not to participate in agricultural activities. One third of the interviewed farmers $(32 \%)$ attributed their low level of participation to the reason that the date of the activity is not suitable for them. The preoccupation with another concern or job is the second important reason for $28 \%$ of the farmers. The three reasons: (Does not know the date of activity, unwillingness to participate and activities do not meet their needs) are other reasons for $40 \%$ of the interviewed farmers not to participate. Again, these reasons should be considered when preparing agricultural extension programs and methodologies.

Table 3: Degree of farmers' satisfaction about the agricultural extension activities

\begin{tabular}{llll}
\hline & $\begin{array}{l}\text { Average degree } \\
\text { of satisfaction }\end{array}$ & SD $^{*}$ & Rank \\
\hline Activity & 2.78 & 1.02 & 7 \\
Agricultural exhibitions & 3.15 & 1.01 & 5 \\
Workshops & 3.19 & 0.78 & 4 \\
Seminars, lectures & & & \\
and discussions & 3.92 & 0.70 & 3 \\
Extension fields & 2.93 & 0.84 & 6 \\
Leaflets & 4.13 & 0.86 & 2 \\
Field visits & 4.35 & 0.76 & 1 \\
Office visits & 3.49 & 0.83 & \\
Total & & & \\
\hline SD*; Standard Deviation; Source: & Prepared by the researchers based \\
on the study survey & &
\end{tabular}


Table 4: Levels of farmers participation according to satisfaction

\begin{tabular}{llr}
\hline Level of participation & Average degree of participation & $(\%)$ \\
\hline High & $4.13:[(4.13+4.35+3.92) / 3]$ & 43 \\
Medium & $3.09:[(3.19+3.15+2.92) / 3]$ & 43 \\
Low & 2.78 & 14 \\
Total & & 100 \\
\hline
\end{tabular}

Source: Prepared by the researchers based on the study survey

Table 5: Reasons prevent farmers from participation in extension activities

\begin{tabular}{llr}
\hline & $\begin{array}{l}\text { No. of farmers } \\
\text { adopts the reason }\end{array}$ & $(\%)$ \\
\hline Deason & 035 & 11 \\
Not suitable date of activity & 102 & 32 \\
Unwillingness to participate & 042 & 13 \\
Activities do not meet their needs & 051 & 16 \\
Preoccupation with another concern & 090 & 28 \\
Total & 320 & 100 \\
\hline
\end{tabular}

Source: Prepared by the researchers based on the study survey

\section{CONCLUSION}

High, medium and low levels of interviewed farmers' participation in agricultural extension activities were noticed. Three activities were high in the degree of farmers' satisfaction indicating high level of farmers' participation. These three activities resembled $43 \%$ of the total investigated activities. Other three activities were medium level and also resembled $43 \%$ of the total investigated activities. The remaining activity was low in participation and resembled $14 \%$ of the total investigated activities. The farmers' overall mean score for participation was 3.49, indicating a positive attitude and high satisfaction toward agricultural extension activities. The most effective category in extension activities participation is the category 40-60 years of age.

Recommendations: The farmers age category of 40-60 is characterized by maturity in decision making and agricultural experience, so specific attention should be made for this category. The inequality of scientific degree of the interviewed farmers requires to be taken in consideration when preparing agricultural extension programs and extension methodologies. Also, attention is to be made to those farmers who consider agriculture as a main job. The date of the activity is not suitable for farmers and the preoccupation with another concern or job resembles $60 \%$ of the reasons for farmers not to participate in agricultural extension activities and should be considered when preparing agricultural extension programs and methodologies. The other three reasons: (Does not know the date of activity, unwillingness to participate and activities do not meet their needs) resembles $40 \%$ of the reasons for the interviewed farmers not to participate.
In the light of the findings from the study, the following recommendations among others were made:

- Extension activities should be planned with full involvement of farmers to increase their level of participation

- Using local leaders as contact farmers could enhance farmer participation

- There should be a drive by the public authorities to educate farmers fully on the objectives, function and advantages of the agricultural extension activities

\section{REFERENCES}

Allahyari, M.S., 2009. Agricultural sustainability: Implications for extension systems. Afr. J. Agric. Res., 4: 781-786.

Antholt, C.H., 1994. Getting Ready for the TwentyFirst Century: Technical Change and Institutional Modernization in Agriculture. 1st Edn., World Bank Publications, Washington, D.C., ISBN: 0821325108, pp: 46.

Chambers, R., A. Pacey and L.A. Thrupp, 1989. Farmer First: Farmer Innovation and Agricultural Research. 1st Edn., Intermediate Technology Publications, London, pp: 218.

Dennehy, N., D.J. Ruane and J.F. Phelan, 2000. Supports and funding for community development projects in the republic of Ireland. J. Int. Agric. Extension Educ., 7: 45-52.

Haverkort, B., J.V.D. Kamp and A. Waters-Bayer, 1991. Joining Farmer's Experiments: Experiences in Participatory Technology Development. 1st Edn., Intermediate Technology Publications, London, ISBN: 1853391018, pp: 269.

Hosseini, S.J.F., M. Niknami and G.H.H. Nejad, 2009. Policies affect the application of information and communication technologies by agricultural extension service. Am. J. Applied Sci., 6: 14781483. DOI: 10.3844/ajassp.2009.1478.1483

Khalil, J., 2007. Agricultural extension and rural development. Afro-Asian Organization for Rural Development, New Delhi, India.

Maunder, A.H., 1972. Agricultural Extension: A Reference Manual. 1st Edn., FAO, Rome, pp: 336.

Seevers, B., 1997. Education Through Cooperative Extension. 1st Edn., Delmar Publishers, Albany, New York, ISBN: 0827371721, pp: 288.

Swanson, B.E., 2006. Extension strategies for poverty alleviation: Lessons from China and India. J. Agric. Educ. Extension, 12: 285-299. DOI: 10.1080/13892240601062488 
Shamsudin, S.B. and T. H. Yap, 2011. Occupational exposure of pesticides on activities of Alanine aminotransferase and $\gamma$-glutamyltranspeptidase in blood among vegetables farmers. Am. Med. J., 2: 87-92. DOI: $10.3844 / \mathrm{amjsp} .2011 .87 .92$

Tella, A., C.O. Ayeni and S.O. Popoola, 2007. Work motivation, job satisfaction, and organisational commitment of library personnel in academic and research libraries in Oyo State, Nigeria. J. Library Philosophy Pract., 4: 1-16.

Tiraieyari, N., K. Idris, J. Uli and A. Hamzah, 2010. Competencies influencing extension workers' job performance in relation to the good agricultural practices in Malaysia. Am. J. Applied Sci., 7: 1379-1386. DOI: 10.3844/ajassp.2010.1379.1386
Vergot, P., G. Israel and E. Mayo, 2005. Sources and channels of information used by beef cattle producers in 12 counties of the Northwest Florida extension district. J. Extension.

Waters-Bayer, A., 1989. Participatory technology development in ecologically-oriented agriculture : some approaches and tools. Agricultural Administration Unit, London. 